\title{
High Resolution CT Imaging in Pathologies of Temporal Bone
}

\author{
Prem Kumar Chidambaram ${ }^{1}$, Vivil Vidya Rajkumar $\mathbf{R}^{2}$, Vinayagam $S^{3}$, Senthil Kumar Aiyappan ${ }^{4}$, \\ Bulabai Karpagam ${ }^{5}$ \\ ${ }^{1}$ Associate Professor, Department of Radiology, ${ }^{2}$ Resident, Department of Radiology, ${ }^{3}$ Professor and Head, Department of \\ Radiology, ${ }^{4}$ Professor, Department of Radiology, ${ }^{5}$ Professor, Department of Radiology, SRM Medical College Hospital, India
}

Corresponding author: Prem Kumar Chidambaram, Associate Professor, Department of Radiology, SRM Medical College Hospital, India

DOI: http://dx.doi.org/10.21276/ijcmsr.2019.4.3.3

How to cite this article: Prem Kumar Chidambaram, Vivil Vidya Rajkumar R, Vinayagam S, Senthil Kumar Aiyappan, Bulabai Karpagam. High resolution CT imaging in pathologies of temporal bone. International Journal of Contemporary Medicine Surgery and Radiology. 2019;4(3):C11-C17.

\section{A B S T R A C T}

Introduction: Diseases of the ear are a common clinical problem, encountered in every day. Clinical examination alone is not sufficient in present days, owing to prevalence, complications and recurrence of various pathologies of the temporal bone, imaging plays a major role in the management and influences the treatment. High-resolution computed tomography (HRCT) offers an excellent resolution, allowing a better understanding of the aetiology, pathology, disease course with early detection of complications. The prospective study aimed to study pathologies of the temporal bone along with their complications on HRCT and to correlate with their surgical findings.

Material and Methods: A prospective study done with a sample size of 90 patients with ear complaints, such as hearing loss, pain, vertigo, ear discharge and tinnitus and referred for HRCT temporal bone were included. Ear trauma and head injury, pregnant women and those unwilling to give consent were excluded. HRCT was done using a GE 128 Slice CT scanner and were followed up for surgical or medical methods of management. Images are reconstructed in the ultra-sharp bone algorithm for image reconstruction, analysed for reporting. The intraoperative findings such as middle ear soft tissue density, ossicular erosion, erosion of scutum, tegmen tympani and facial canal, fistulous communication between the middle ear and lateral and posterior semicircular canal. Above findings were analyzed using standard statistical methods.

Results: There is an excellent radio-surgical correlation in diagnosing and differentiating cholesteatoma from granulation tissue, identifying malleus erosion, incus erosion, tegmen tympani erosion, scutum erosion, EAC erosion, sigmoid plate dehiscence, high riding jugular bulb, mastoid status/erosion. Moderate to poor radio-surgical correlation was noted in identifying LSCC fistula, stapes erosion and facial canal erosion.

Conclusion: HRCT is a valuable imaging modality through which pre-operative assessment of temporal bone pathologies can be done efficiently with reasonable accuracy, cost and precision for making surgical decisions. Hence it helps the surgeon to decide the course of action in particular clinical problem.

Keywords: Cholesteatoma, Middle Ear, Computed Tomography

\section{INTRODUCTION}

The temporal bone is a complex anatomic structure containing the organs of hearing and balance. ${ }^{1,2}$ Diseases of the temporal bone are a common entity. Clinical examination alone is not sufficient in present days, owing to prevalence, complications and recurrence of various pathologies of the temporal bone, imaging plays a major role in the management and influences the treatment. ${ }^{3}$ Using special algorithms high-resolution computed tomography (HRCT) offers an excellent resolution. ${ }^{1,4}$ Hidden areas of the middle ear such as sinus tympani and facial recess are well appreciated in $\mathrm{HRCT}^{5}$, allowing better understanding of the aetiology, pathology, disease course with early detection of complications which alters treatment modality and has considerably reduced the morbidity and mortality pertaining to lesions of the temporal bone. $^{6}$

In addition to cholesteatoma, a very serious condition of the middle ear, HRCT plays a major role in the presurgical evaluation of other pathologies such as chronic suppurative otitis media (TT type), malignant otitis externa ${ }^{7}$, otosclerosis s $^{8,9}$ and anatomical variations like high riding jugular bulb etc. The prospective study aimed to study pathologies of the temporal bone along with their complications on HRCT and to correlate with their surgical findings.

\section{MATERIAL AND METHODS}

This was a prospective study, done in our institution from January 2016 to August 2017 with a sample size of 90, after due clearance from the institutional ethical committee. Written informed consent was obtained from all patients prior to the study procedure or data collection. Patients of all age group with ear complaints, such as hearing loss, pain, vertigo, ear discharge and tinnitus referred for HRCT temporal bone were included. Patients with a recent history 
of ear trauma and head injury, pregnant women and those unwilling to give consent were excluded.

HRCT Temporal bone done using a GE (General Electric, Boston, USA) Optima 660 series 128 Slice CT scanner. These patients were followed up for surgical or medical methods of management. Those who underwent surgery following imaging within one month period were included in our study.

After taking complete history and consent, the patient was prepared for the procedure, asked to lie supine in the scan table and advised not to make any movements. Images were acquired in helical mode to reduce movement artefacts. Axial projections were obtained by serial $1 \mathrm{~mm}$ sections of the temporal bone with the plane along the line joining the infra-orbital rim and external auditory meatus, perpendicular to the table. The images were reconstructed in $0.625 \mathrm{~mm}$ thin sections. In average, the entire imaging process took about 4 min to complete. After the imaging process was completed scan table was moved out of the gantry and patients were shifted out. Images were analyzed in sagittal, coronal and axial reconstructions and followed up for management.

\section{Scan protocol}

Topogram: Position: Supine; kV: 120; mA: 80. Helical section temporal bone: Matrix: 512 x 512; FOV:14-24 cm; Slice thickness:0.625 mm; 120 kv,200 mA; Pitch - 0.531, Gantry rotation speed: 0.8 seconds.

Images were reconstructed in the ultra-sharp bone algorithm for image reconstruction, analysed for reporting, as the bone algorithm is superior to the standard algorithm in the assessment of tiny bony structures with increased spatial resolution without degrading the image quality and being routinely used in assessing temporal bone and lung parenchyma.

The intraoperative findings such as middle ear soft tissue density, ossicular erosion, erosion of scutum, tegmen tympani and facial canal, fistulous communication between the middle ear and lateral and posterior semicircular canal. Other findings like the erosion of carotid canal, sigmoid plate, mastoid process erosion, inner ear lucency/sclerosis, TM joint pathology, etc (Table-1).

Above findings were tabulated and analyzed using standard statistical methods which included Microsoft Excel and SPSS software. Imaging and surgical findings were analyzed with cross tabulation and sensitivity, specificity, positive predictive value and negative predictive value were assessed and their association and agreement were established by using chi square and kappa.

\section{RESULTS}

Among 90 study participants, the majority was in the second decade of life(25\%); followed by the fourth decade 21\%. Males outnumber females by $100 \%$; the majority of the study population were males about $65.6 \%$ (59) and females were $34.4 \% .{ }^{31}$ The left side was the most affected in $53.3 \%$, followed by right in $31.1 \%$ and bilateral were $15.6 \%$.

Majority of patients suffered from hearing loss of about $60 \%(54)$ followed by discharge about $52.2 \%$ (47), pain $32.2 \% \mathrm{v}(29)$ and vertigo $34.4 \%{ }^{31}$ Among the diseases evaluated, cholesteatoma was the commonest (92\%), followed
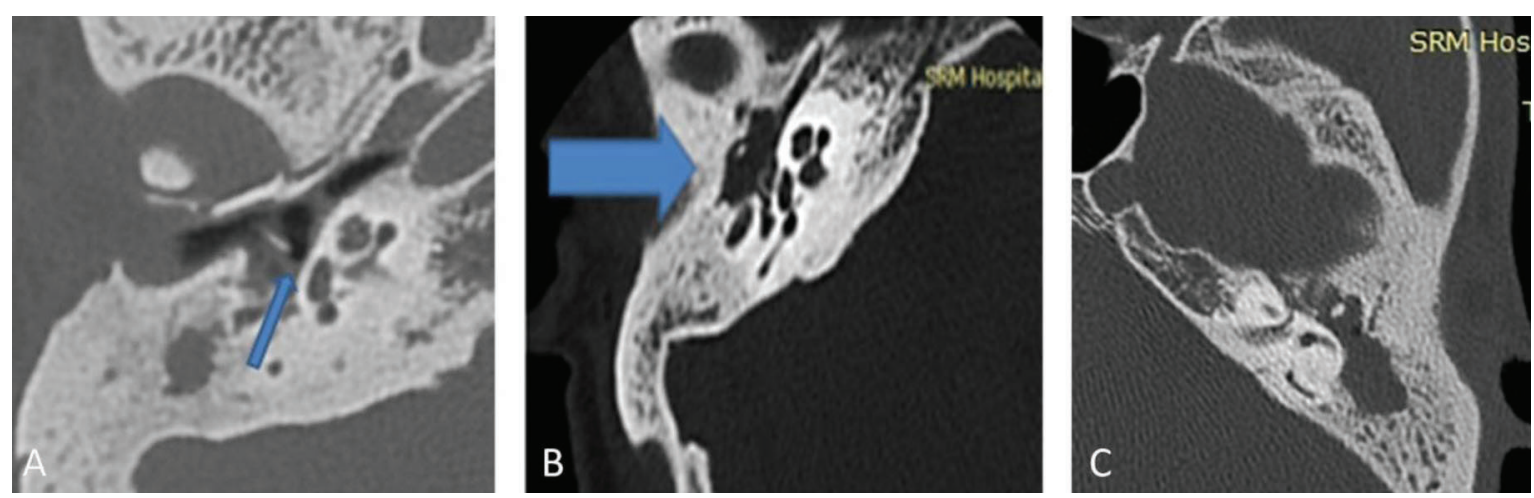

Figure-1: A. HRCT of the right temporal bone(axial section) at the level of ossicles shows the long process of incus and stapes erosion(blue arrow). Soft tissue density also is seen in the middle ear. B. The long process of incus erosion and soft tissue density in the middle ear. C. Ossicular erosion, aditus ad antrum widening with loss of figure 8.
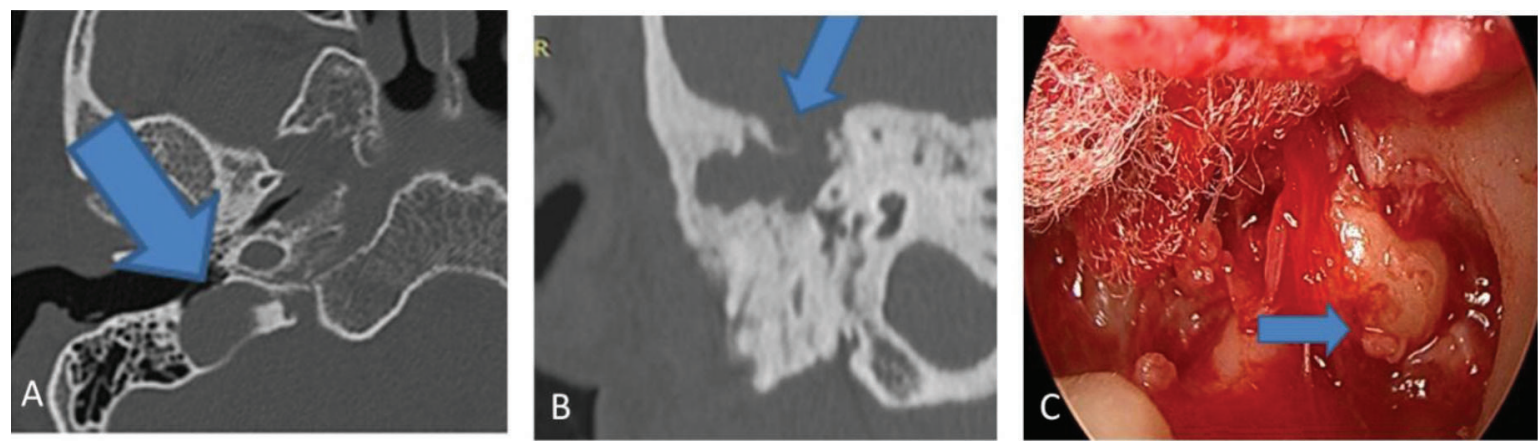

Figure-2: A. HRCT temporal (axial section) shows a dehiscent jugular bulb. B. Tegmen tympani erosion (blue arrow). C. Malleus erosion. 


\begin{tabular}{|l|l|l|}
\hline External ear & $\begin{array}{l}\text { Cartilageneous Part } \\
\text { Mass } \\
\text { Collection } \\
\text { Granulation tissue }\end{array}$ & $\begin{array}{l}\text { Bony Part } \\
\text { Erosion } \\
\text { Cholesteatoma } \\
\text { TM Joint }\end{array}$ \\
\hline Middle ear & $\begin{array}{l}\text { Ossicles - Erosion } \\
\text { Soft tissue density } \\
\text { Facial canal }\end{array}$ & $\begin{array}{l}\text { Scutum, } \\
\text { Tegmen tympani } \\
\text { Sigmoid plate }\end{array}$ \\
\hline Inner ear & $\begin{array}{l}\text { Cochlea } \\
\text { Lucency }\end{array}$ & $\begin{array}{l}\text { Semicircular canal } \\
\text { Jugular bulb } \\
\text { Carotid canal }\end{array}$ \\
\hline Mastoid process & Pnumatised & Collection, Sclerosis, Erosion \\
\hline Brain Abscess, Dural vein thrombus & Nasopharynx & Para nasal sinuses \\
\hline \multicolumn{2}{|r|}{ Table-1: Features to be studied in HRCT temporal bone imaging. } \\
\hline
\end{tabular}

\begin{tabular}{|l|c|c|c|c|}
\hline Findings & Sensitivity & Specificity & PPV & NPV \\
\hline Malleus erosion & 94 & 90 & 92 & 92 \\
\hline Incus erosion & 99 & 87 & 97 & 93 \\
\hline Stapes erosion & 65 & 85 & 56 & 89 \\
\hline Scutum erosion & 100 & 92 & 91 & 100 \\
\hline Tegmen tympani erosion & 87 & 99 & 92 & 97 \\
\hline Facial canal dehiscence & 100 & 97 & 60 & 100 \\
\hline Lscc fistula & 100 & 98 & 100 & 98 \\
\hline Sigmoid dehiscence & 75 & 100 & 100 & 87 \\
\hline Diff cho/grn & 92 & 100 & 50 & 100 \\
\hline Foot pate thick & 100 & 98 & 100 & 100 \\
\hline Mastoid erosion. & $100 \quad 100$ & & \\
\hline \multicolumn{2}{|l|}{ Table-2: Sensitivity, specificity, positive and negative predictive values of middle ear components on a comparison between HRCT } \\
\end{tabular}

by malignant otitis(4\%) and otosclerosis(2\%).

For middle ear soft tissue opacity, the external auditory canal (EAC) and tegmen tympani erosion, significant association seen between Surgery and HRCT. Both tests were correctly picked up EAC and tegmen tympani erosion vs normal with Chi sq $=90$ and 62.95 respectively and $p<0.0001$. HRCT accurately diagnosed 4 cases of EAC erosion which was found to be eroded intraoperatively as well with a sensitivity and specificity of $100 \%$. And HRCT accurately predicted $92 \%$ of cholesteatoma cases with a sensitivity of $92 \%$, the specificity of $100 \%$, the positive predictive value of $100 \%$, the negative predictive value of $87 \%$ and Kappa of $91 \%$. HRCT accurately predicted tegmen tympani erosion in $81 \%$ of cases with sensitivity of $87 \%$, specificity of $99 \%$, positive predictive value of $92 \%$, negative predictive value of $97 \%$.

There was significant association between Surgery and HRCT for high riding jugular bulb (Figure 2) chi sq = $59.75, p<0.0001$. There is $88 \%$ agreement between these two tests.HRCT accurately predicted $80 \%$ of high riding jugular bulb cases with sensitivity of $89 \%$, specificity of $99 \%$, positive predictive value of $88 \%$, negative predictive value of 98\%.

In evaluation of mastoid, there was significant association between Surgery and HRCT with chi sq $=90$, $\mathrm{p}<0.0001$. HRCT accurately predicted mastoid erosion in $100 \%$ of cases with $100 \%$ sensitivity, specificity, positive and negative predictive value.

For sigmoid plate erosion, significant association seen between surgical findings and imaging with chi sq $=45.48$ and $p<0.0001$. There is $85 \%$ agreement between these two tests. HRCT accurately predicted sigmoid plate erosions in $75 \%$ of cases with a sensitivity of $75 \%$, specificity of $100 \%$, positive predictive value of $100 \%$, the negative predictive value of $98 \%$

There was a significant association between Surgery and HRCT for Facial canal and lateral semicircular canal (LSC) erosion with chi sq $=29.32$ and 35.78 respectively, $\mathrm{p}<0.001$. There is $65 \%$ of agreement between these two tests, and HRCT predicted facial canal erosion in only $50 \%$ of cases with sensitivity of $100 \%$, specificity of $97 \%$, positive predictive value of $50 \%$, negative predictive value of $100 \%$ There is $74 \%$ of agreement between these two tests for LSC erosion. HRCT predicted 60\% of LSCC fistula with a sensitivity of $100 \%$ specificity of $98 \%$, the positive predictive value of $60 \%$ and a negative predictive value of $100 \%$.

HRCT accurately detected TM joint erosion in 100\% of cases with sensitivity, specificity, positive, the negative predictive value of $100 \%$.

Significant association was seen between Surgery and HRCT for scutum erosion (Figure 1 ) chi sq $=71.7, p<0.0001$. There was $91 \%$ of agreement between these two tests; for stapes erosion. chi $\mathrm{sq}=20.24, \mathrm{p}<0.0001$. HRCT predicted stapes erosion in $43 \%$ of cases. Agreement between two are $49 \%$; for malleus erosion chi sq $=60.32, p<0.0001$ and there was $84 \%$ of agreement between these two tests and for incus erosion. 


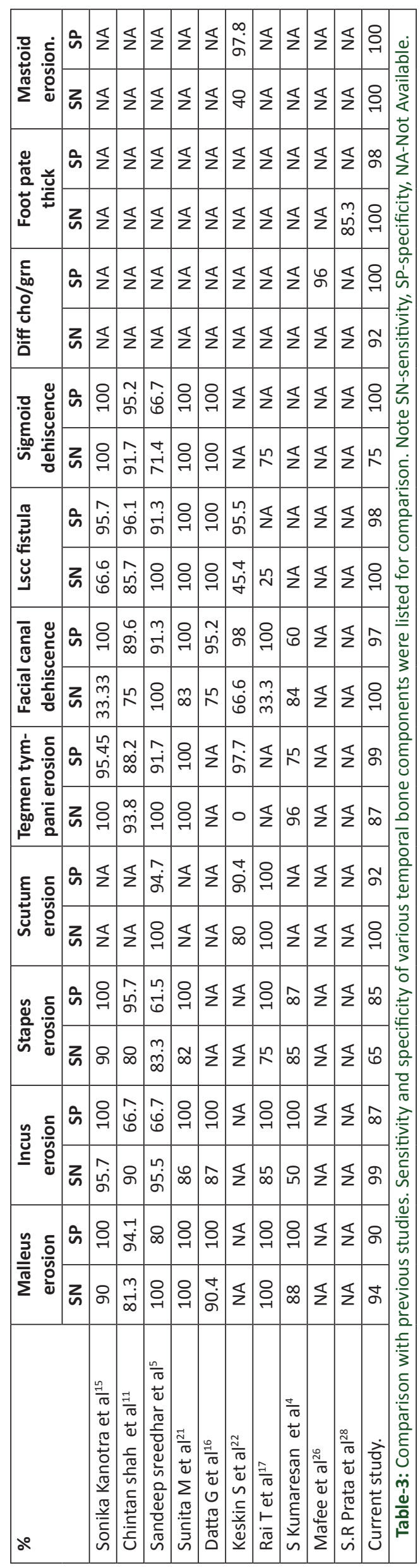

chi $\mathrm{sq}=69.29, \mathrm{p}<0.0001$ with $88 \%$ agreement between the two tests (Table 2).

\section{DISCUSSION}

High resolution Computed tomography helps in assessing the anatomical extension of infections and its complications, detecting congenital abnormalities and also helps in detecting loss of surgical landmarks owing to previous surgeries. Among various pathologies of the temporal bone, cholesteatoma is the most common especially in younger patients. The overall prevalence of middle ear diseases in males outnumbers females. However, in community studies, no gender differences were reported in the prevalence of CSOM as the major temporal bone pathology. A high prevalence of males over females was reported in hospitalbased studies indicates that females patients were reluctant for initial treatment and come late to hospitals.

In patients with cholesteatoma, clinical otologic examination and HRCT were used to assess presence, extension and complications. As YuZ et a $1^{10}$ described the detection of early bone and scutum erosions.

HRCT accurately diagnosed cholesteatoma in $91 \%$ of cases with good sensitivity and specificity based on the presence of non-dependent tissue mass in epitympanum, mastoid antrum and Prussack's space and scutum or ossicular erosion. Chintan Shah et a ${ }^{11}$ and Mafee et al identified aditus ad antrum widening with loss of its figure of 8 appearances with mastoid antrum expansion also added value. Swartz et al ${ }^{12}$ reported that out of 54 patients with cholesteatoma ossicular erosion was found only in $50 \%$ of cases in both by imaging and intraoperatively.

HRCT accurately predicted $94 \%$ of cases of incus erosion. Incus is the most eroded ossicle in our study similar to reports by Amit Shankhwar et a $1^{13}$ and Rohit Vallabhaneni et al. ${ }^{14}$ Sonika Kanotra et al. ${ }^{15}$ Datta et $\mathrm{al}^{16}$ and Rai et a $\mathrm{a}^{17}$ observed slightly low sensitivity of $87 \%$ and $85 \%$. HRCT accurately predicted in $43 \%$ of cases of malleus erosion which was found to be eroded intraoperatively as well. $11 \%$ of cases were missed and found to be eroded intraoperatively; overdiagnosed in 7 cases which were found to be normal. Stapes is the least eroded. Sandeep Sreedhar et $\mathrm{al}^{5}$ and Mehrdad Rocha et $\mathrm{a}^{18}$ reported poor radiologic-surgical correlation in stapes erosion and stated that the small size of the bone may be the cause in poor detection by HRCT.

Scutum erosion was accurately predicted in $91 \%$ of cases similar to Gaurano et al ${ }^{19}$ and Chakenahalli $\mathrm{P}$ et al, Sandeep Sreedhar, et $\mathrm{al}^{5}$, Rocher et $\mathrm{a}^{20}$ and Dr Amit Shankhwar et al..$^{13}$ In contrast, Sunitha $\mathrm{M}$ et al ${ }^{21}$ reported no correlation for scutum erosion. Suat Keskin et $\mathrm{a}^{22}$ described that differences in imaging and intraoperative findings may be due to inappropriate angles of the coronal sections, partial volume effects of the soft tissues. HRCT accurately predicted LSCC fistula with excellent sensitivity and good specificity. Mardassi $\mathrm{Ali}^{23}$ also states that LSCC is the most common semicircular canal to be eroded in cholesteatoma because of its close proximity to the medial wall of attic anatomically. Similar incidence also noted by Chuni Lal Thukral et $\mathrm{al}^{3}$ who reported sensitivity and specificity of $100 \%$ and $97.73 \%$ 
while Datta et $\mathrm{al}^{16}$ and Sunita, $\mathrm{M}$ et $\mathrm{al}^{21}$, Alzoubi et $\mathrm{al}^{24}$, Chee and Tan et $\mathrm{a}^{25}$, Mafee et $\mathrm{al}^{26}$, and Rocher et $\mathrm{al}^{20}$ reported HRCT to be $100 \%$ sensitive.

$75 \%$ of cases with sigmoid plate dehiscence were accurately detected by HRCT with relatively lower sensitivity when compared to other studies. Chintan Shah et $\mathrm{a}^{11}$, reported sensitivity and specificity of HRCT in detecting sigmoid erosion to be $91.7 \%$ and $95.25 \%$ respectively. Sonika Kanotra et $\mathrm{al}^{15}$, reported the sensitivity, specificity, positive and negative predictive value to be $100 \%$.

HRCT accurately predicted tegmen tympani erosion in $81 \%$ of cases. Sonika Kanotra et al ${ }^{15}$ reported a sensitivity of $100 \%$ in detecting tegmen tympani erosion by HRCT which was higher than the current study. A similar specificity rate of $95 \%$ was reported by Gerami et $\mathrm{al}^{27}$ and negative predictive value of $100 \%$ was reported by Prata et $\mathrm{a}^{28}$ and Datta et al. ${ }^{16}$ A poor sensitivity rate of $\mathrm{HRCT}$ to detect tegmen tympani erosion was also reported by Jackler et $\mathrm{al}^{29}$ and $\mathrm{O}^{\prime}$ Reilly et a ${ }^{30}$, while a moderate association was seen by Vlastarakos et $\mathrm{al}^{31}$ and Chee and Tan et al..$^{25}$ Suat Keskin et $\mathrm{al}^{22}$ reported that out of 11 cases diagnosed as tegmen tympani erosion by HRCT there was no erosions noted intraoperatively and missed one case which was found to be eroded intraoperatively. And states that the poor radiosurgical correlation for tegmen tympani erosion may be due to partial volume of both the tympanic cavity and cerebral soft tissue may be overestimated as a defect on coronal sections which became thinned as a result of chronic inflammatory processes.

Another common cause of conductive deafness is otosclerosis. The HRCT helps in diagnosing otosclerosis and delineating from other causes of conductive deafness has vastly improved. The sensitivity and specificity of HRCT in diagnosing stapedial otosclerosis by evaluating quantitative thickening of stapes footplate was assessed in patients suspected of otosclerosis. HRCT sensitivity in detecting the site of otosclerotic foci in the present study as no intraoperative correlation is seen. 5 patients with a clinical diagnosis of otosclerosis underwent HRCT temporal bones. The thickness of the footplate was measured and the site of the lesion value; only two patients underwent surgery. Intraoperatively the footplate thickness was assessed and graded according to a visual scale.

HRCT accurately predicted thickened foot plate in 50\% of cases with a sensitivity of $100 \%$ and specificity of $98 \%$ using imaging criteria of otosclerosis, which include increased thickness of foot plate $>0.6 \mathrm{~mm}$, grey foot plate(otospongiotic), hypodensity anterior to oval window, widened oval window and partial or complete obliteration of oval window by thickened footplate. S. R. Priya et $\mathrm{al}^{9}$, detected the sensitivity foot plate thickening is $85.3 \%$. The sensitivity of detecting otosclerosis by evaluating footplate thickness may increase with thickness. In the current study there was no correlation made between otosclerotic lesions imaged by HRCT and that was seen intraoperatively. The sensitivity of detecting otosclerotic lesion depends upon the stage of the lesion. Swartz et $\mathrm{al}^{32}$, studied the utility of CT scanning in the assessment of fenestral otosclerosis, found about $70 \%$ of patients had a positive finding of bony excrescence at or adjacent to the oval window. In 2001,
Fraysse et $\mathrm{al}^{133}$ described the sensitivity of $91.3 \%$ in finding otosclerosis on CT. Naumann et $\mathrm{al}^{134}$, found the sensitivity of $85 \%$ in localizing otosclerotic focus in 30 patients suspected to have otosclerosis.

HRCT accurately predicted mastoid erosion in 100\% of cases. Suat Keskin et a ${ }^{22}$, reported a sensitivity of $40 \%$ and specificity of $97.8 \%$. Chintan Shah et $\mathrm{al}^{11}$ mentioned the importance of mastoid pneumatization in deciding the type of surgery i.e.canal wall down or canal wall up procedure.

To identify high riding jugular bulb is extension superior to the tympanic annulus or within $2 \mathrm{~mm}$ of the internal auditory canal. Preoperative identification of a high riding jugular bulb helps the surgeons to plan the surgery and to take appropriate measures to avoid life-threatening complications. HRCT accurately predicted high riding jugular bulb in $80 \%$ of cases with good sensitivity (89\%), similar findings were reported by Atmaca $S$ et a $1^{35}$ who reported a prevalence of $15 \%$ and Atilla $\mathrm{S}$ et a $\mathrm{a}^{36}$ reported $20 \%$ (Table 3).

There is an excellent radio-surgical correlation in diagnosing and differentiating cholesteatoma from granulation tissue, in identifying malleus erosion, incus erosion, tegmen tympani erosion, scutum erosion, EAC erosion, sigmoid plate dehiscence, high riding jugular bulb, mastoid status/erosion. Moderate to poor radio-surgical correlation was noted in identifying LSCC fistula, stapes erosion and facial canal erosion. These disparities in case of identifying stapes erosion could be probably due to the small size of the bone with associated soft tissue density around it making it difficult to identify, partial volume effects or limitation in surgery to reach the bony contour may lead to poor identification of LSCC fistula causing poor radio-surgical correlation and oblique orientation, small size, presence of developmental dehiscence particularly when abutted by soft tissues made it difficult in identifying facial canal erosion.

\section{CONCLUSION}

The results of the present study indicate that HRCT is a valuable imaging modality through which pre-operative assessment of temporal bone pathologies can be done efficiently with reasonable accuracy, cost and precision for making surgical decisions. HRCT helps in defining the disease, extent and complications of almost all middle ear pathologies. Hence it helps the surgeon to decide the course of action in particular clinical problem.

Even though the current study emphasizes the value of HRCT in pathologies of the temporal bone, it is limited due to small sample size, short study duration and the limited spectrum of clinical diagnosis. Hence, larger sample size and longer study period and evaluating structures in multiplanar reconstruction will definitely add more value.

\section{REFERENCES}

1. Bagul M. High-resolution Computed Tomography Study of Temporal Bone Pathologies. Headache. 2016;32(1):26.66.

2. Fatterpekar GM, Doshi AH, Dugar M, Delman BN, Naidich TP, Som PM. Role of 3D CT in the evaluation of the temporal bone. Radiographics: a 
review publication of the Radiological Society of North America, Inc. 2006;26 Suppl 1:S117-32.

3. Thukral CL, Singh A, Singh S, Sood AS, Singh K. Role of High Resolution Computed Tomography in Evaluation of Pathologies of Temporal Bone. Journal of clinical and diagnostic research: JCDR. 2015;9(9):TC07-10.

4. Kumaresan S, Nirmala M. Usefulness of Pre-operative High-resolution Computed Tomography in Middle Ear Cholesteatoma.

5. Sreedhar S, Pujary K, Agarwal AC, Balakrishnan R. Role of high-resolution computed tomography scan in the evaluation of cholesteatoma: A correlation of highresolution computed tomography with intra-operative findings. Indian Journal of Otology. 2015;21(2):103.

6. Vivek R, Gunasekaran P, Sethurajan S, Adaikappan M. Evaluation of HRCT temporal bone and pathologies. Journal of Evolution of Medical and Dental Sciences. 2014;3(52):12118-27.

7. Gold S, Som PM, Lucente FE, Lawson W, Mendelson M, Parisier SC. Radiographic findings in progressive necrotizing "malignant" external otitis. The Laryngoscope. 1984;94(3):363-6.

8. Purohit B, Hermans R. Imaging in otosclerosis: A pictorial review. Insights into imaging. 2014;5(2):24552.

9. Priya S, Singh P, Upreti L, Vaid L. High resolution computed tomography in stapedial otosclerosis. Indian Journal of Otolaryngology and Head \& Neck Surgery. 2013;65(3):505-11.

10. Yu Z, Han D, Gong S, Wang Z, Zhang L. The value of scutum erosion in the diagnosis of temporal bone cholesteatoma. Acta oto-laryngologica. 2010;130(1):4751.

11. Shah C, Shah P, Shah S. Role of HRCT temporal bone in pre operative evaluation of choesteatoma. 2014.

12. Swartz JD. Cholesteatomas of the middle ear. Diagnosis, etiology, and complications. Radiologic Clinics of North America. 1984;22(1):15-35.

13. Shankhwar A, Dixit Y, Shukla P, Nagar A. High Resolution Computed Tomography Evaluation of Temporal Bone Lesions.

14. Vallabhaneni R, Srinivasa Babu C. HRCT temporal bone findings in CSOM: our experience in rural population of South India. IOSR J Dent Med Sci. 2016;15(3):49-53.

15. Kanotra S, Gupta R, Gupta N, Sharma R, Gupta S, Kotwal S. Correlation of high-resolution computed tomography temporal bone findings with intra-operative findings in patients with cholesteatoma. Indian Journal of Otology. 2015;21(4):280.

16. Datta G, Mohan C, Mahajan M, Mendiratta V. Correlation of preoperative HRCT findings with surgical findings in Unsafe CSOM. IOSR Journal of Dental and Medical Sciences (IOSR-JDMS). 2014;13(1):120-25.

17. Rai T. Radiological study of the temporal bone in chronic otitis media: Prospective study of 50 cases. Indian Journal of Otology. 2014;20(2):48.

18. Rogha M, Hashemi SM, Mokhtarinejad F, Eshaghian A, Dadgostar A. Comparison of Preoperative Temporal Bone CT with Intraoperative Findings in Patients with
Cholesteatoma. Iranian journal of otorhinolaryngology. 2014;26(74):7-12.

19. Gaurano JL, Joharjy IA. Middle ear cholesteatoma: characteristic CT findings in 64 patients. Annals of Saudi medicine. 2004;24(6):442-7.

20. Rocher P, Carlier R, Attal P, Doyon D, Bobin S, editors. Contribution and role of the scanner in the preoperative evaluation of chronic otitis. Radiosurgical correlation apropos of 85 cases. Annales d'oto-laryngologie et de chirurgie cervico faciale: bulletin de la Societe d'otolaryngologie des hopitaux de Paris; 1995.

21. Sunita M, Sambandan A. Importance of Pre-Operative HRCT Temporal Bone in chronic suppurative otitis media. Odisha J Otorhinolaryngol Head Neck Surg. 2015;9(1):10-3.

22. Keskin S, Çetin H, Töre HG. The correlation of temporal bone CT with surgery findings in evaluation of chronic inflammatory diseases of the middle ear. European Journal of General Medicine. 2011;8(1).

23. Ali M, Nabil M, Safa K, Sameh M, Cyrine Z, Ghassen $\mathrm{C}$, et al. Limits of conventional temporal bone computed tomography in the management of cholesteatoma otitis media: Report of 96 cases. The Egyptian Journal of Otolaryngology. 2014;30(2):73-7.

24. Alzoubi FQ, Odat HA, Al-balas HA, Saeed S. The role of preoperative CT scan in patients with chronic otitis media. European Archives of Oto-rhino-laryngology. 2009;266(6):807-9.

25. Chee N,Tan T. The value of pre-operative high resolution CT scans in cholesteatoma surgery. Singapore medical journal. 2001;42(4):155-9.

26. Mafee MF, Levin BC, Applebaum EL, Campos $\mathrm{M}$, James CF. Cholesteatoma of the middle ear and mastoid. A comparison of CT scan and operative findings. Otolaryngologic Clinics of North America. 1988;21(2):265-93.

27. Gerami H, Naghavi E, Wahabi-Moghadam M, Forghanparast K, Akbar MH. Comparison of preoperative computerized tomography scan imaging of temporal bone with the intra-operative findings in patients undergoing mastoidectomy. Saudi medical journal. 2009;30(1):104-8.

28. Prata AAS, Antunes ML, de Abreu CEC, Frazatto R, Lima BT. Comparative study between radiological and surgical findings of chronic otitis media. Arquivos Internacionais de Otorrinolaringologia. 2011;15(01):072-8.

29. Jackler RK, Dillon WP, Schindler RA. Computed tomography in suppurative ear disease: a correlation of surgical and radiographic findings. The Laryngoscope. 1984;94(6):746-52.

30. O'reilly B, Chevretton E, Wylie I, Thakkar C, Butler $\mathrm{P}$, Sathanathan $\mathrm{N}$, et al. The value of CT scanning in chronic suppurative otitis media. The Journal of Laryngology \& Otology. 1991;105(12):990-4.

31. Vlastarakos PV, Kiprouli C, Pappas S, Xenelis J, Maragoudakis P,Troupis G, et al. CT scan versus surgery: how reliable is the preoperative radiological assessment in patients with chronic otitis media? European Archives of Oto-rhino-laryngology. 2012;269(1):81-6.

32. Swartz J, Faerber E, Wolfson R, Marlowe F. Fenestral 
otosclerosis: significance of preoperative CT evaluation. Radiology. 1984;151(3):703-7.

33. Shin Y, Deguine O, Cognard C, Sevely A, Manelfe C, Fraysse B. Reliability of CT scan in the diagnosis of conductive hearing loss with normal tympanic membrane. Revue de laryngologie-otologie-rhinologie. 2000;122(2):81-4.

34. Naumann IC, Porcellini B, Fisch U. Otosclerosis: incidence of positive findings on high-resolution computed tomography and their correlation to audiological test data. Annals of Otology, Rhinology \& Laryngology. 2005;114(9):709-16.

35. Atmaca S, Elmali M, Kucuk H. High and dehiscent jugular bulb: clear and present danger during middle ear surgery. Surgical and Radiologic Anatomy. 2014;36(4):369-74.

36. Atilla S, Akpek S, Uslu S, Ilgit ET, Işik S. Computed tomographic evaluation of surgically significant vascular variations related with the temporal bone. European journal of radiology. 1995;20(1):52-6.

Source of Support: Nil; Conflict of Interest: None

Submitted: 16-05-2019; Accepted: 12-06-2019; Published online: 15-07-2019 